\title{
Identification of Changes in Mechanical Properties of Human Axial System Due to Stress and Relaxation Regime
}

\author{
Martin Svoboda ${ }^{1}$, Kateřina Van der Kamp², Karel Jelen², Milan Sapieta ${ }^{3}$ \\ ${ }^{1}$ Faculty of Mechanical Engineering, Jan Evangelista Purkyně University in Ústí nad Labem, Czech Republic, E-mail: \\ martin.svoboda@ujep.cz \\ ${ }^{2}$ Faculty of Physical Education and Sport, Charles University in Prague, Czech Republic, E-mail: jelen@ftvs.cuni.cz \\ ${ }^{3}$ Faculty of Mechanical Engineering, University of Žilina, Slovak Republic, E-mail: milan.sapieta@fstroj.uniza.sk
}

The aim of this work was to verify the applicability of the TVS (Transfer Vibration through Spine) methodology for registration of changes in viscoelastic characteristics of the axial system. The detection method consists in applying $\gamma$ pulse pulses with a half-width of $5 \mathrm{~ms}$ and then a harmonic excitation of continuously varying from $5 \mathrm{~Hz}$ to $160 \mathrm{~Hz}$ on vertebrae $\mathrm{C7}$ and $\mathrm{L5}$. This ripple is transmitted along the axial system and acceleration of all the spinous processes of the vertebrae is sensed by accelerometer sensors to propagate the wave between $\mathrm{C7}$ and $\mathrm{S1}$. On the basis of measured data (input excitation and its sensed response on spinous processes), the change of total viscoelastic parameters of the spine was evaluated before and after monotonous or other spinal strain or before and after relaxation. Existing results confirmed the TVS method is suitable for detection of mechanical changes of the axial system. It was proven transmission of ripples through the axial system of a person also changes by the influence of alternations created by monotonous or physical strain or conversely relaxation.

Keywords: vibration, monotonous strain, axial system, mechanical properties, spine, vibration transfer

\section{Introduction}

The environment of mechanical vibrations is a stress factor, which puts a person under pressure. Vibrational load of a person can be defined as a sum of all reactions of a person exposed to a vibrational stress. This includes biodynamic behavior of the individual parts of a body and physiological reactions of circulation, respiration, muscle system and central nervous system together with subjective perception of intensity of vibrations, lowered efficiency, and even health-related harm [1].

Nowadays, there is a lot of attention directed towards the increase of safety while driving a car and the indicators signaling decrease of drivers' alertness, which could detect onset of micro-sleep. It is known alertness and reaction time already decrease after less than an hour of driving. Some of the major causes of reduced alertness are long monotonous load of an operator, mental and physical conditions, and other factors. Long driving time and monotonous static load causes discomfort, and it is a reason for higher occurrence of back pain, back injuries and incapacity for work among professional drivers. Subjectively, monotony manifests itself by feelings of somnolence, loss of concentration, lowered interest, lethargy, apathy, and boredom, and at the same time it reduces the activity of a CNS with the absence of stimuli, while operational activity is conducted automatically and controlled by subcortical centers [2].

Discomfort of motion system while driving occurred with $77.8 \%$ of drivers, and it manifests especially in the spinal area $(72.1 \%)$. Furthermore, it appears in many forms starting with discomfort and ending with pain. Statistically, it has been proven there are differences for each gender in occurrence and localization of discomfort in the neck and lower back region. Women tend to feel discomfort subjectively more often than men. There is a $60 \%$ chance discomfort takes form in the neck area of those who had their backrest set in an angle between $110^{\circ}$ and $120^{\circ}$. So called latent discomfort, which manifests itself as fatigue in the moment when we do not subjectively perceive it as discomfort, is very dangerous. Unfortunately, an objective fatigue indicator has not been discovered yet. In addition, it has been proven indicators evaluating alertness while driving are not associated with an objective improvement of drivers' ability to drive. Monotony of the roadway and its surroundings might lead to deterioration of one's driving ability. Reduction of drivers' alertness can be detected by other means than the use of EEG. Discomfort acts like a distinctive indicator of musculoskeletal issues. It is dependent on mechanical tension of soft tissue and local chemical changes, but also on mental and social factors. The main reasons for drivers' medical problems are body posture and vibrations while driving, and impact of the roadway surface and control. Examination of the spine position of a person resting in a car seat with well-designed ergonomic backrests shows the body is tightly pressed against backrest on the dorsal side of the upper lumbar vertebrae. The friction connected with this pressure suppresses tension and tensile strength on the level of these vertebrae. On the other side the lowest lumbar vertebrae, which are located between a lower backrest and seat, can move more freely axially. That is why the tension in tensile strength and pressure mentioned above should substantially appear in lower intervertebral discs (L4-L5 and L5-S1) [3-6].

The aim of this work was to verify applicability of non-invasive methodology by measuring the transmission of vibrations through the spine (hereinafter TVS) for registration of changes of elastic spinal properties. Moreover, we wanted to check the usefulness of the TVS method for the demonstration of mechanical changes of spinal properties after exposure to different types of spinal load (vibration, monotonous static and physical load) or conversely after an extended period of relaxation. 


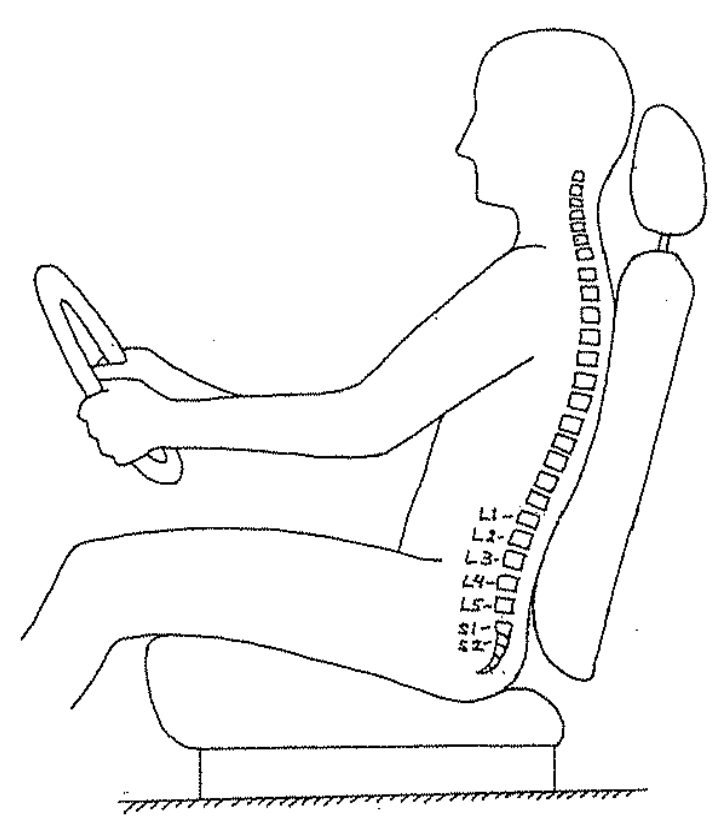

Fig. 1 Rough position of a spine with regards to a seat [5]

\section{Methodology of measurements}

The first of the experiments was removing anamnesis and kinesiological analysis conducted by a physiotherapist before and after driving.

The flagship methodology used in the experiment was adjusted non-invasive measurement of vibration transfer between individual segments of spine, which is carried out before and after driving. Furthermore, the measurement was done before as well as after completing physical stress, and it was also performed after a long period of lying on a bed relaxing.

Basic information about the driver was collected (age, height, weight, percentage of body fat, chest width, pelvis width, anamnesis, pain and changes in perception as a result of spine defects including use of contraception and pregnancy for female subjects). Kinesiological examination was conducted afterwards with a special focus on individual dorsal and lumbar vertebrae (their excessive deviation in latero-lateral and sagittal regions, palpable soreness of spinous processes including data about chronic pain and pain during static and dynamic pressure). In addition, tests indicating an ability of unrolling spine into flex (symptom of Cepoj, Otto's inclinational index, symptom of Schober and Stibor, symptom of Thomayer), extension (Otto's reclining index), and lateroflexion (lateroflexion of torso to the left and right) were included in the kinesiological examination. Measurement of ability to unroll spine in particular directions is commonly used in physiotherapeutic practice and is taught as an examination methodology in order to assess the 'health' of a spine. In the case of a spinal disorder (degenerative or functional disorder), the spine does not unroll into a particular direction in this segment, and the measured distance is not extended.

A potential change of mechanical properties of an axial system as a result of monotonous load while driving, after physical exertion or after a long period of bed relaxation, was registered.

The TVS method lies in application of excitation with $\gamma$ pulses with $5 \mathrm{~ms}$ half-width. The excited system starts to oscillate on one or multiple own frequencies. The oscillations are transmitted along the spine, and the resonance frequency is mainly based on rigidity of bonds of the vertebrae, which is influenced by $\gamma$ pulse. The greater the rigidity of bonds in relation to the neighboring vertebrae is, the higher the resonance frequency is to be expected. Intervertebral disc, which is transversely deformed during oscillation transfer, has a role as a shock absorber of transmitted vibrations. [8].

After measuring of $\gamma$ pulses lasting 20 seconds in total, the harmonic excitation of the vertebrae follows with a frequency periodically changing from $5 \mathrm{~Hz}$ to $160 \mathrm{~Hz}$. Excitation influences $\mathrm{C} 7$ vertebrae and transmits itself along the axial system. Accelerometric sensors are used to scan acceleration on spinous processes of Th1 to S1 vertebrae. Additionally, excitation is applied to L5 vertebrae and the response is scanned by accelerometers on spinous processes of S1 and L4 to C7 vertebrae. The position of a vibrator and accelerometric sensors is shown in Figure 2 with a display of vertebral column scheme.

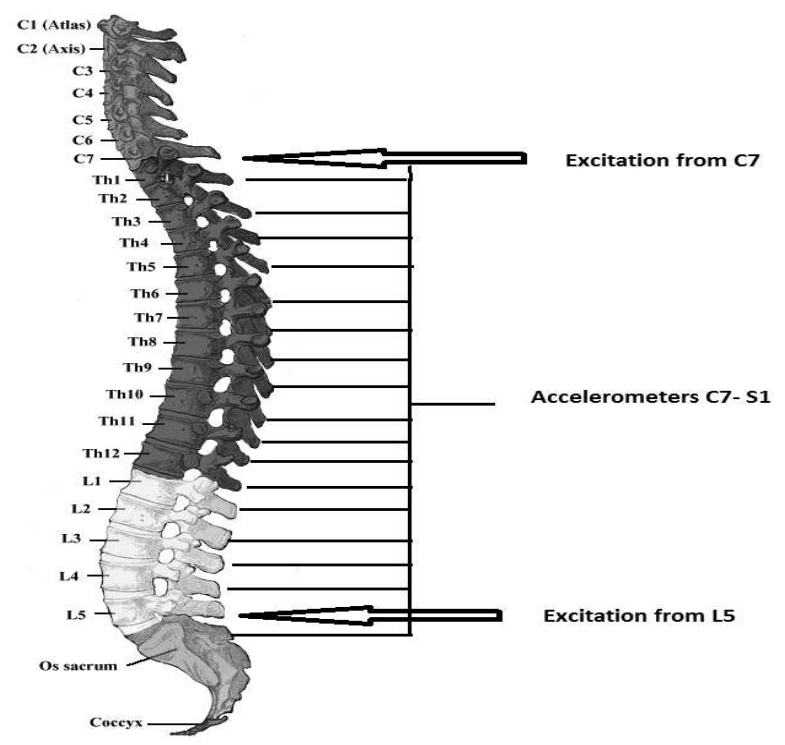

Fig. 2 Scheme of vertebral column

During the experiment a position of lying on the stomach with maximally relaxed skeletal muscles on an antidecubitus mattress was used, which is a different position than while driving or during physical and other kinds of load, however, this way oscillation of other parts of the body, especially limbs and head was eliminated, and thus devaluation of a measured signal was minimized. Furthermore, a different body position examined while measuring was excluded, which would occur, if the subjects were tested while sitting. We also avoided any undesirable activity of skeletal muscles by instructing our subjects to be fully relaxed during the measuring.

Before the start of measuring transfer of vibrations, spinous processes of individual vertebrae from C7 to S1 were marked. We had already been marking the vertebrae 
while the subject was lying on their stomach since the position of spinous processes and skin changes if the person is standing or lying. Searching for spinous processes is complicated if the test subjects have a higher amount of body fat, which then covers them with a thicker layer of soft tissue.

After marking the spinous processes, an accelerometric sensor was attached to each of them. Excitation was implemented by an electromechanical converter - vibrator. Contact between the vibrator and spinous processes was achieved by sufficient thrust of the vibrator, which was scanned and moved around 3.5N (350g). In Fig. 3 the arrangement of the experiment is depicted together with the placement of the accelerometric sensors and the actuating device on the L5 vertebrae; the subject is lying on the anti-decubitus mattress.

The actual measurement of TVS consisted of four phases:

1. Excitation of $\mathrm{C} 7$ by $\gamma$ pulse- impact on the spinous processes with $5 \mathrm{~ms}$ half-width; the sequence of tapping on $\mathrm{C} 7$ process lasts about 20 seconds; the subject is not breathing; transfer of oscillations on all spinous processes from the neighboring Th1 to $\mathrm{S} 1$ is being scanned.

2. Harmonic excitation of C7- Spectrum of vibrations ranging between $5-160 \mathrm{~Hz}$ is excited on the spinous process of $\mathrm{C} 7$ vertebrae by the attached vibrator. The frequency of excited vibrations was changing smoothly from $5 \mathrm{~Hz}$ to $160 \mathrm{~Hz}$ in order to prevent adaptation of the system to a particular frequency and also to prevent overload of the nerve-muscle apparatus caused by resonance oscillation. This 3-minute sequence of vibration was repeated three times in a single measurement. Oscillations excited this way were spreading along the axial system, where the velocity and acceleration of spinous processes from Th1 to S1 were scanned by accelerometric sensors.

3. Excitation of L5 by $\gamma$ pulse- the impact on spinous process with $5 \mathrm{~ms}$ half-width; the sequence of tapping on L5 process lasts about 20 seconds; the subject is not breathing, acceleration was scanned on the neighbouring $\mathrm{S} 1$ spinous process and on the L4-C7 vertebrae processes.

4. Harmonic excitation of L5 (spectrum of frequencies and their progress were the same as with C7 vertebrae excitation). Oscillations excited this way were spreading along the axial system, where acceleration was scanned on the $\mathrm{S} 1$ spinous process and on the L4-C7 vertebrae processes.

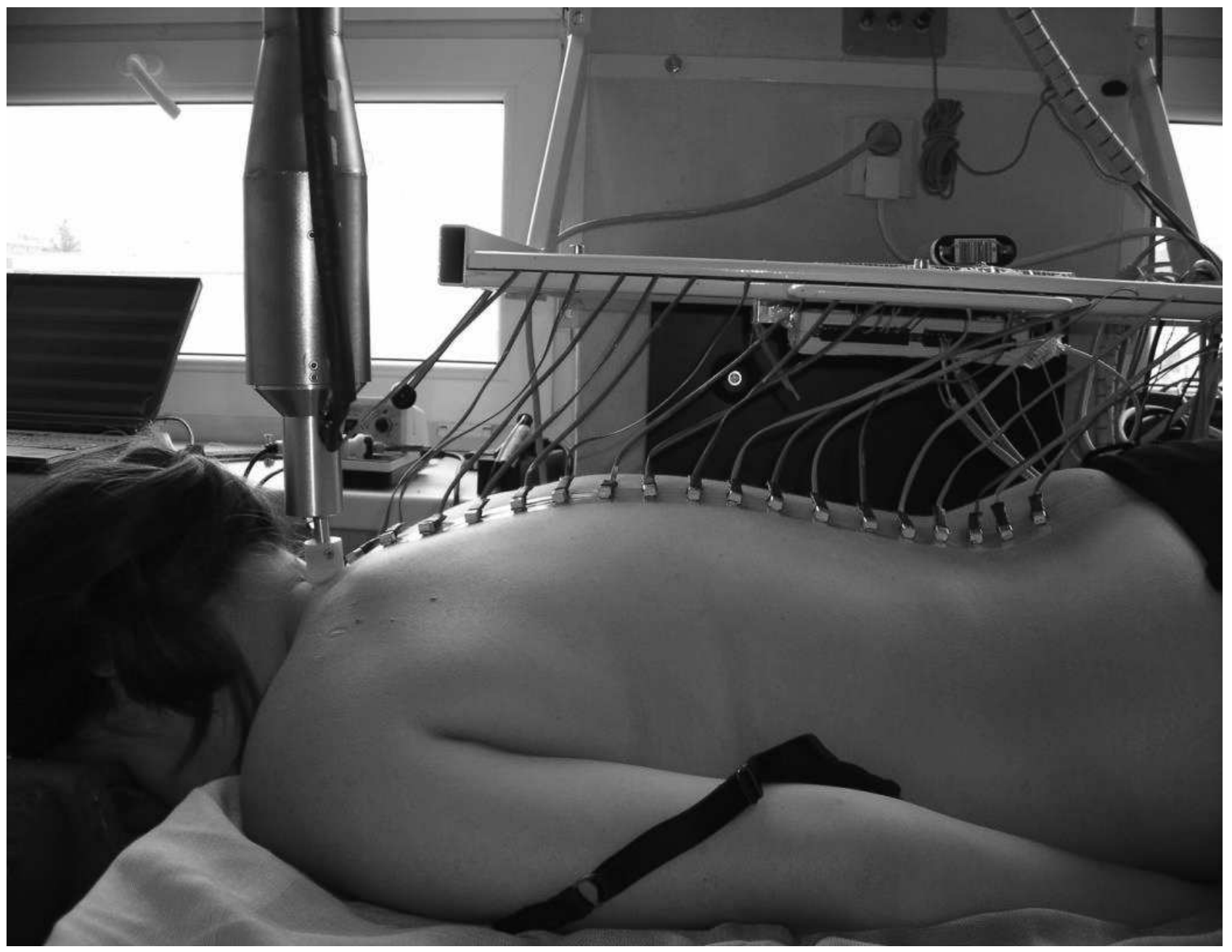

Fig. 3 Arrangement of the experiment; placement of the accelerometric sensors and actuating device 
The TVS method was used to get measurements before and after a long period of relaxation. During the measurement of before and after relaxation, kinesiological examinations were conducted first. Afterwards, accelerometric sensors were attached, and we carried out the first measurement in a horizontal position on an anti-decubitus mattress. This first measurement and the time to attach the sensors took 45 minutes, and the subject was lying down relaxed in the process. After the horizontal relaxation the second measurement was conducted without reattaching of the sensors, which lasted 20 minutes.

\section{The results of measurements}

Overall, nine subjects were tested, and with some of them the measurements had to be done repeatedly. In total there were 30 measurements always before and after different kinds of strain, before and after driving, and prior and post relaxing.

During the measurements we used excitation with rising and falling frequencies and found out the response of the axial system to excitation with rising and falling frequencies was very similar. The character of graphs and the resonance peaks were matching during the excitation with rising and falling frequencies. In the following figures we can observe examples of individual measurements.

In Fig. 4 we can see transfer of vibrations between L3 and L1 segments during excitation and also transfer from C7 vertebrae with rising frequencies from 20 to $100 \mathrm{~Hz}$ prior strain and falling frequencies from 100 to $20 \mathrm{~Hz}$ prior strain. Moreover, there is transfer of vibrations in the same figure between L3 and L1 segments during excitation from the $\mathrm{C} 7$ vertebrae with rising frequencies from 20 to $100 \mathrm{~Hz}$ prior strain and falling frequencies from 100 to $20 \mathrm{~Hz}$ prior strain. During the following measurements we then used the average from the excitation with rising and falling frequencies prior strain and the average from the excitation with rising and falling frequencies post strain.

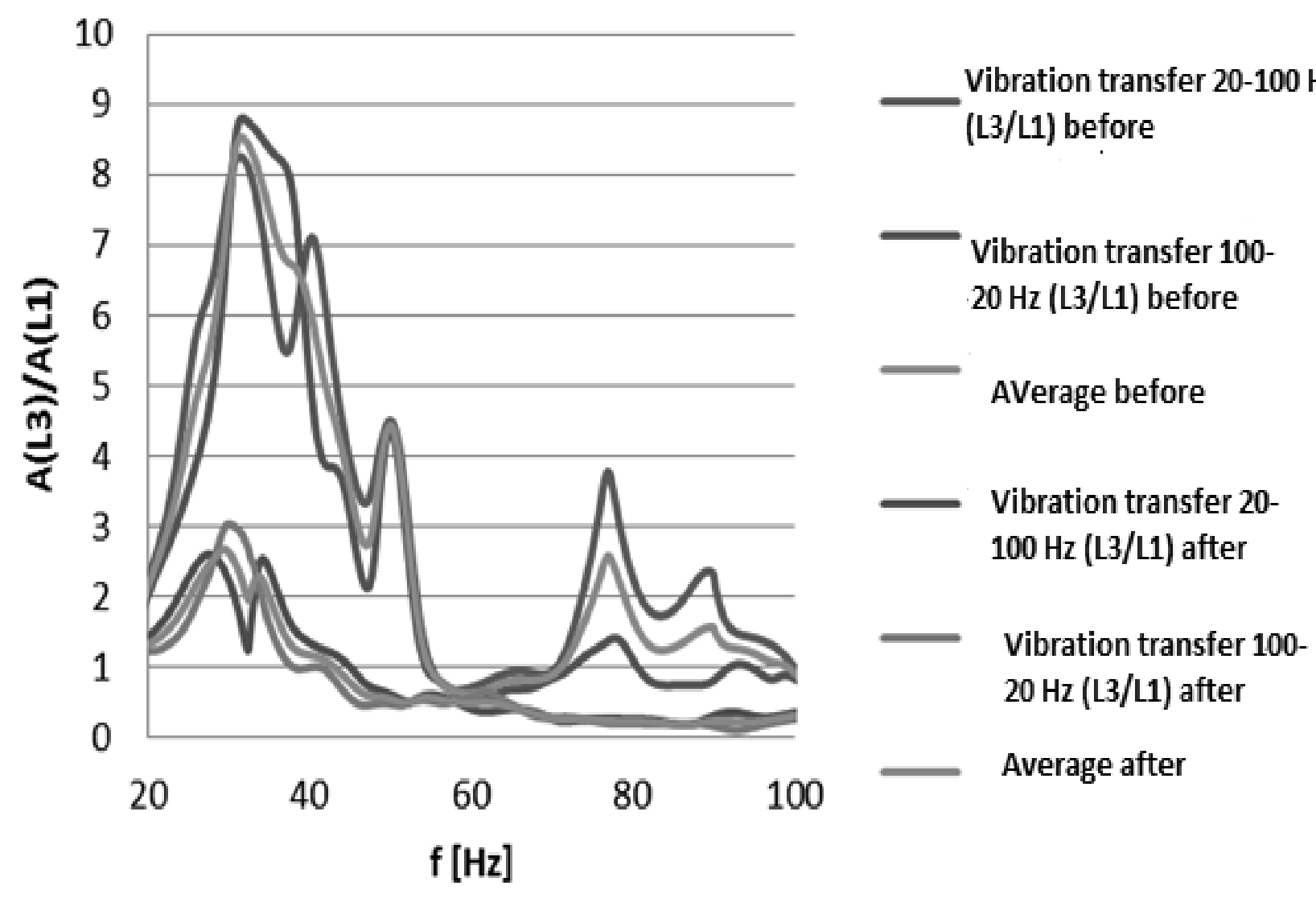

Fig. 4 Excitation of $C 7$ vertebrae with rising and falling frequencies prior and post strain with the same subject; the average from the excitation with rising and falling frequencies prior and post strain with a single subject in the L3/L1 segment

In Fig. 5 we can observe the proportion of amplitudes scanned in the segment between Th10 and Th6 vertebrae during the excitation from $\mathrm{C} 7$ vertebrae by rising frequencies $20-100 \mathrm{~Hz}$ prior and post strain and by falling frequencies $100-20 \mathrm{~Hz}$ prior and post strain. In the graph the average from excitation of rising and falling frequencies prior and post strain is also depicted. It is clear in figure 4 and 5 that the response of the axial system is not dependent on whether the excitation is done via rising or falling frequencies, and that is why we used only the average from the response to excitation with rising and falling frequencies in the following graphs as it is shown in the two different segments of spine in figure 4 and 5. 


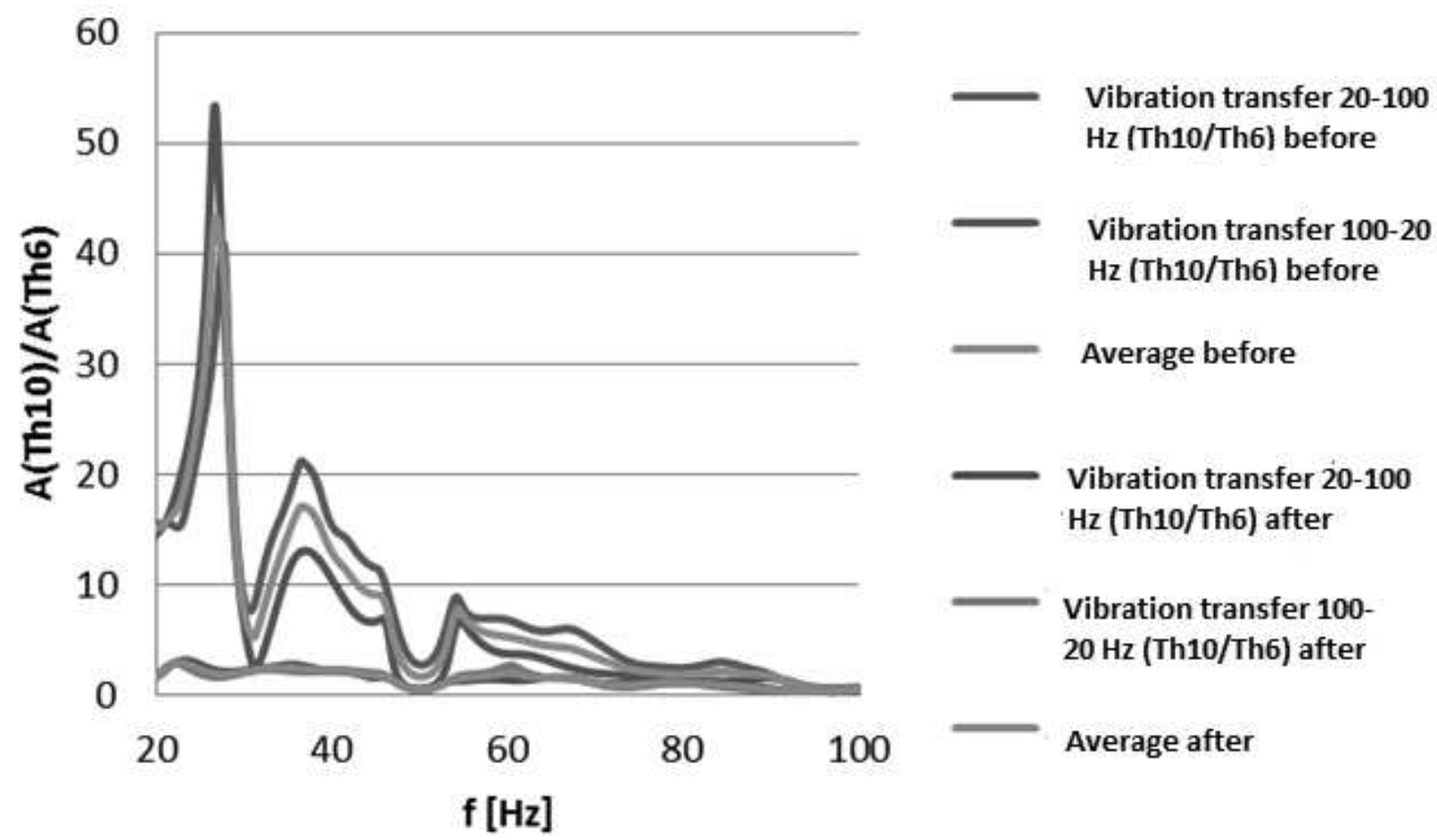

Fig. 5 Excitation from $C 7$ with rising and falling frequencies prior and post strain and the average from excitation with rising and falling frequencies prior and post strain in thoracic segment of spine between Th10 and Th6

For clarity of results we compared measurements of excited C7 vertebrae with individual subjects. In our graphs there is always actuating frequency on the $\mathrm{x}$ axis and the proportion of acceleration amplitudes scanned on particular vertebrae on axis $y$. In the numerator there are always scanned data from the vertebrae farther from the excited vertebrae. In addition, in the denominator there are always scanned data from the vertebrae closer to the excited vertebrae. The proportion on the $y$ axis then always expresses vibration transfer between particular vertebrae. If we swapped the proportion, we would get the damping amount on the y axis. The greater the proportion value of the amplitudes between the compared vertebrae is, the greater the vibration transfer between particular vertebrae becomes and the lower the damping with the subject after driving in the segment between L1 and Th10 vertebrae is. In the same segment, there is higher damping and lower transfer prior driving in comparison with the same segment post driving. The excitation by vibrations was performed on $\mathrm{C} 7$ vertebrae in this case.

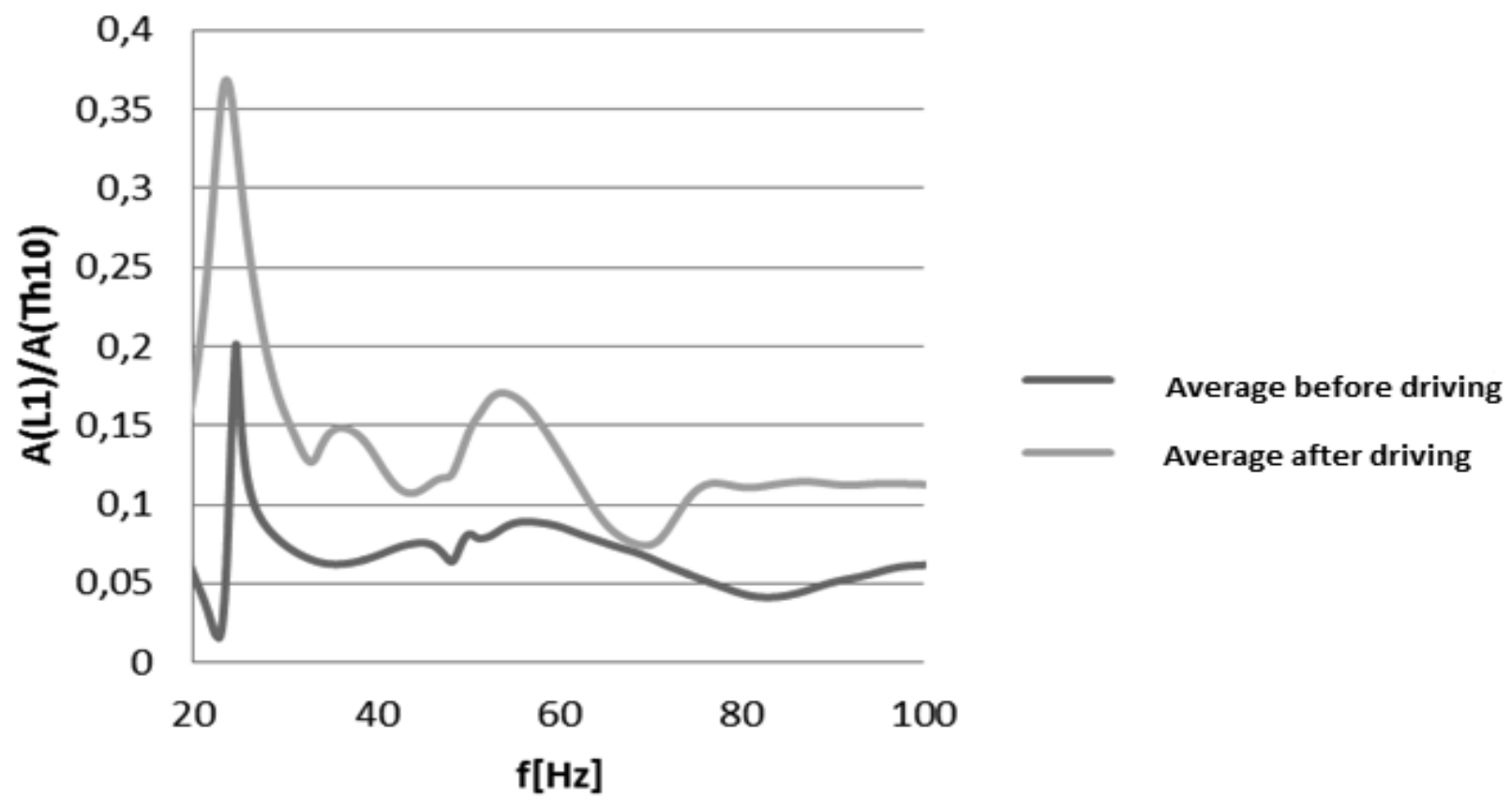

Fig. 6 Response to excitation from C7 vertebrae in the segment between L1 and Th10 vertebrae of a driver before and after driving for 2 hours. The responses are average from excitation by rising and falling frequencies 


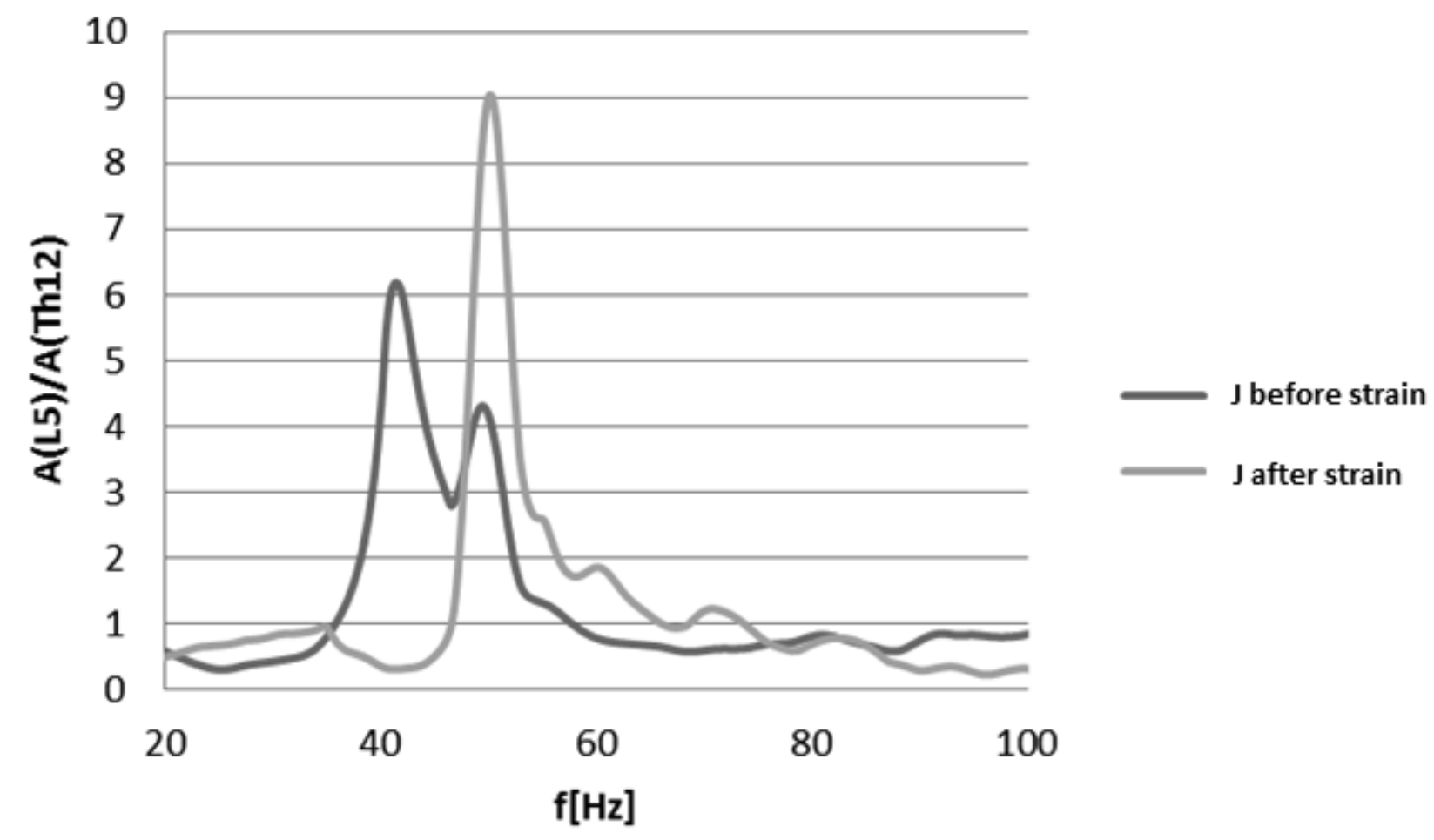

Fig. 7 Subject J-age 22; before and after 2 hour physical strain. Excitation was performed from C7 vertebrae; proportion of amplitudes in the segment L5-Th12

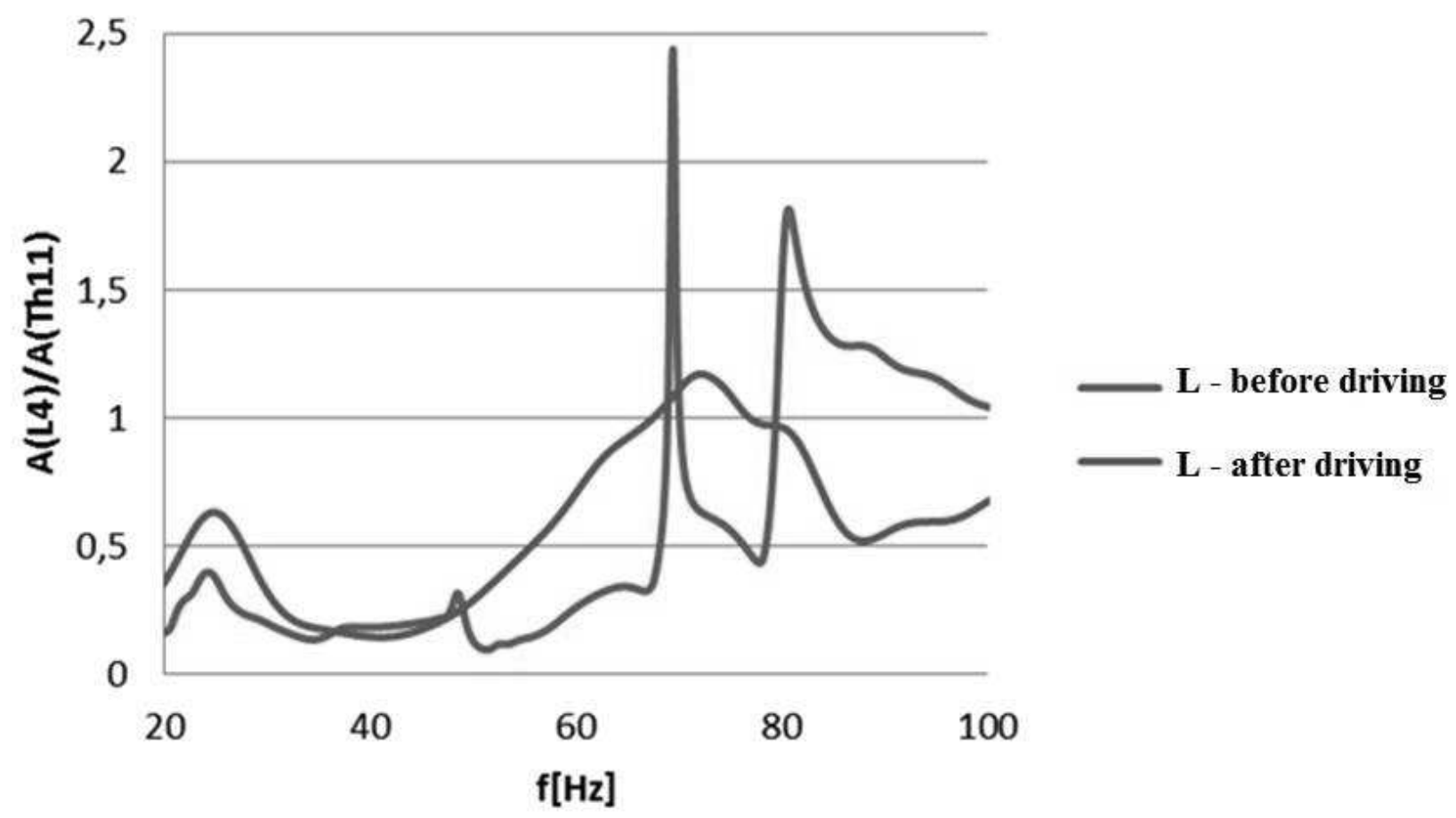

Fig. 8 Subject L-age 22; excitation was performed from C7 vertebrae; transfer was scanned between L4 and Th11 vertebrae.

In figure 7 we can see the viscoelastic properties of subject $\mathbf{J}$ do not change that much in that segment before and after strain.

In the graph in figure 8 there is a response to vibrational excitation of a 22 year-old subject. Looking at subject $\mathrm{L}$ there are obvious resonant maximums with both measurements before and after driving. Connections on spine are bendable, flexible and well oscillated. In figure 9 (Panska and col. 2012) we can see the comparison of a young spine (year of birth 1994- age 18), which oscillates in this segment, with the spine of a subject born in 1934 (age 78), which acts like a single unit. The connections on spine do not oscillate with any apparent maximums and the curve is rather flat. With the increasing size of 
resonant frequency the spine ability to transmit mechanical strain also rises; the value of elastic constant is generally higher $-\mathrm{E}\left[\mathrm{J} / \mathrm{m}^{3}\right]-$ density of mechanical energy. A shift to higher resonant frequencies is visible in the graph in figure 9 with the youngest subject.

The different age of testing subjects creates diverse transfer of vibrational excitation through the axial system.
While with younger subjects the axial system reacts flexibly - connections on spine are soft and oscillate; we can observe great resonance peaks (fig. 8). With older subjects the spine reacts as a single unit- a rod; connections on the spine are not that flexible and we cannot see resonance peaks. Resonance peaks are shifting upwards to higher frequencies with younger subjects (Fig.9).

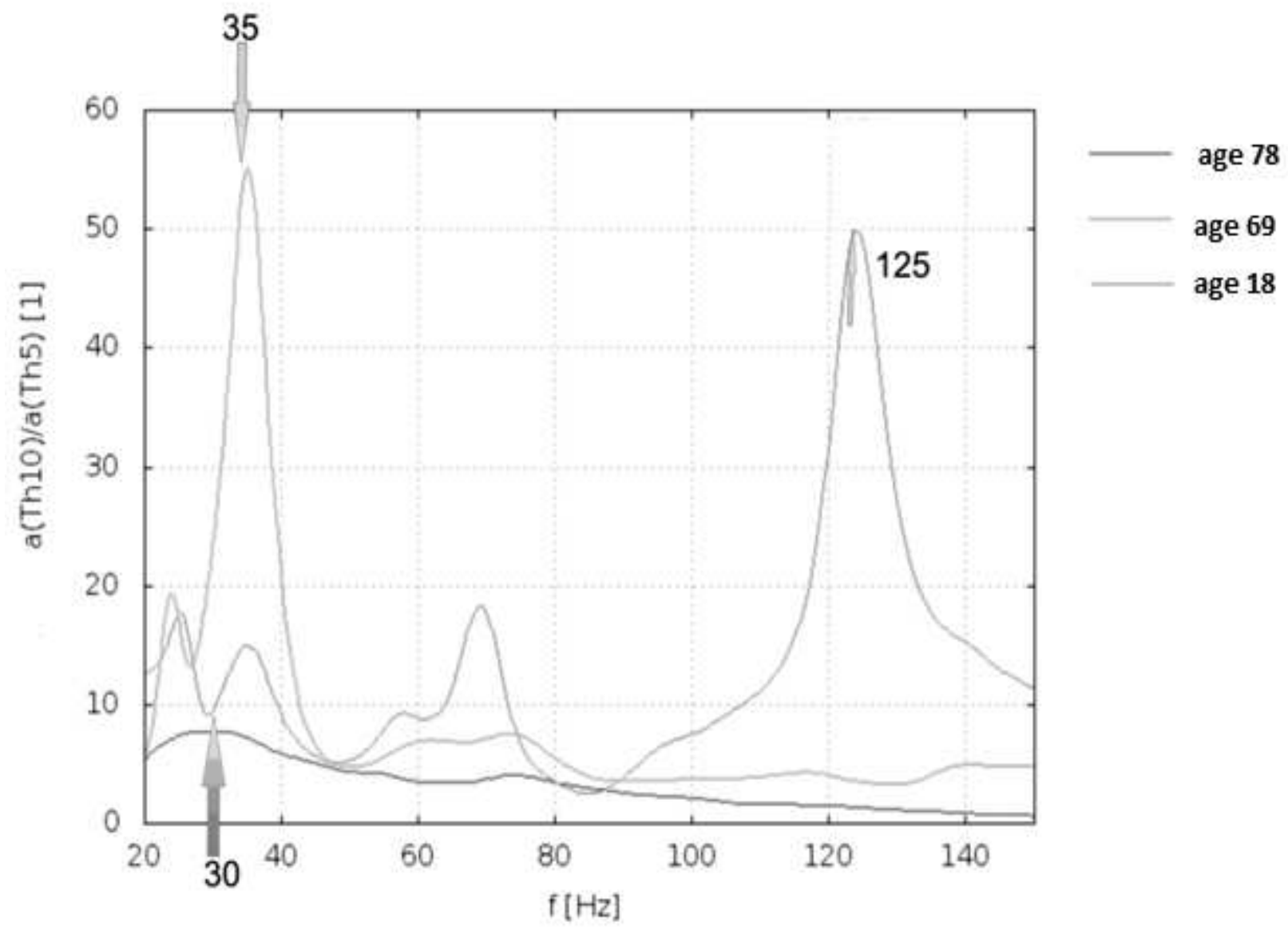

Fig. 9 Transfer in the region between Th10 and Th5 vertebrae of three subjects of various age [7].

\section{Discussion and conclusion}

This work was mainly focusing on the question whether it is possible to detect changes of mechanical and rheological properties within the axial system by using the TVS method, and if this method enables registration of changes of mechanical properties of the axial system caused by strain or conversely relaxation.

Based on measured data it can be deduced young, healthy and flexible spines as a whole oscillate just like an elastic rod. The higher its elasticity is, the more mechanical energy it is capable of absorbing during strain and the less apparent the influence of fatigue is as a result of the strain; the connections on spine are bendable and relaxed and they oscillate well. If the spine is less flexible, the ability to oscillate is decreased; vibrational excitation response is worse and its connections are less relaxed and less bendable.

Elasticity determines resonant frequencies and it is determined mainly by vertebrae and their connections. Viscosity is determined mostly by muscles and ligaments.
Shear modulus of cartilage determines the resonant frequency the most, while the muscle component depends on the frequency minimally. Viscosity (muscles, ligaments) is responsible for attenuation of transverse waves and elastic module (vertebrae and their connections on the spine) is responsible for transfer.

On the basis of collected data it turned out healthy and flexible spines tend to have a resonant frequency between $40-60 \mathrm{~Hz}$ or more (Fig. 7). The majority of graphs (e.g.Fig 9) show significant resonant maximums on higher frequencies. Tested subjects were below the age of 30 . The spine reacts to mechanical waves and oscillates unlike the curves of subjects who were between the age of 69 and 78. The spine of a 69-year old subject has resonant frequency lower than $30 \mathrm{~Hz}$ and spine of a 78 -year old subject does not have any noticeable resonant peaks and its connections are not flexible nor do they oscillate.

It can be stated it is possible to detect changes of mechanical properties of the spine using the TVS method. The created model based on the main characteristics of the studied system showed it is possible to find a relation 
among the overall elastic module of a human spine - E and viscosity $\gamma$ and phase shift- $\psi$ of input signal. The model proved wave transmission or loss of wave transmission is dependent on the properties of the system while going through it. The change of mechanical properties of the system is reflected on the velocity of a wave passing through it.

Based on the acquired results of all tested subjects it was found there are changes in mechanical properties of the axial system and in vibrational transfer through the particular system after all kinds of strain (physical strain and monotonous static strain in a vehicle); the TVS method is able to detect those changes.

\section{Acknowledgments}

The article originated with contribution of grant support nr. UJEP-IGA-TC-2019-48-04-2- Jan Evangelista Purkyne University in Usti nad Labem and was also supported by project: SGS 4820615 2013-48-01.

\section{References}

[1] DUPUIS, H. (1989). Biodynamic behavior of the trunk and the abdomen during whole-body vibration. Acta Anaesthesiol. Scand., 1989. Suppl.90: 34-38

[2] GILBERTOVÁ, S., MATOUŠEK, O. (2002). Ergonomie, optimalizace lidské činnosti, Grada: Praha, 2002. ISBN 80- 247- 0226- 6.

[3] RAVNIK, D., OTÁHAL, S. (2005). Discomfort appearance and assesment during car driving, Neurodynamics and Neuroinformatics Studies (Second book on Micro Sleeps), Neural Network World - edice monografií, ICS AS CR : Prague 2005, 194-213, ISBN:80-903298-3-7, EAN 97880-903298-3-6.

[4] SMIDT,E.A. a spol. (2009). Drivers' misjudgement of vigilance state during prolonged monotonous daytime driving. Accident analysis and prevention, 2009. 41(5): 1087-1093
[5] LARUE, G.S. (2010). Predicting effects of monotony on driver's vigilance, Queensland University of Technology, disertační práce, 2010

[6] JOHNSON, D.A., NEVE, M. (2001). Analysis of possible lower lumbar strains caused by the structural properties of automobile seats, a review of some recent technical literature. J. of Manipulative Physiol. Ther., 2001. 24(9): 582-8

[7] PANSKÁ, Š., KLOUČKOVÁ, K., ZEMAN, J., MAREŠOVSKÝ, L., JELEN, K. (2012). Mechanické zatěžování a stárnutí axiálního systému člověka: Identifikace změn pojivových tkání metodou TVS, Sbornik príspěvků Stárnutí 2012, s.16

[8] ZEMAN, J. (2008) Metody neinvazivního měření vibrační přenosové funkce lidské páteře in vivo $\mathrm{v}$ poloze na břiše, dizertační práce, 2008

[9] VONDRÁŠEK, D., HADRABA, D., MATĚJKA, R., LOPOT, F., SVOBODA, M., JELEN, K. (2018). Uniaxial tensile testing device for measuring mechanical properties of biological tissue with stress-relaxation test under a confocal microscope, In: Manufacturing Technology, Vol. 18, No. 5 (2018) pp 866-872, ISSN: 1213-2489

[10] BITTNER, V., ŠTRYNCL, R., JELEN, K., SVOBODA, M. (2018). Mathematical model of the RRR anthropomorphic mechanism for 2D biomechanical analysis of a deep squat and related forms of movement, In: Manufacturing Technology, Vol. 18, No. 5 (2018) pp 704-708, ISSN: $1213-2489$

[11] BITTNER, V., TUČEK, R., PANSKÁ, Š., SVOBODA, M., JELEN, K. (2017). Using the fourier transform in the analysis of vibration load tests of heterogeneous mechanical systems, Manufacturing Technology, Vol. 17, no. 6 (2017), ISSN: 1213-2489 